\title{
Techniques, assessment, and effectiveness of bariatric surgery in combating obesity
}

This article was published in the following Dove Press journal:

Open Access Surgery

20 October 2010

Number of times this article has been viewed

\author{
Dimitrios K Papamargaritis \\ Dimitrios J Pournaras \\ Carel W Le Roux \\ Imperial Weight Centre, Imperial \\ College London, London, UK
}

Correspondence: CarelW Le Roux Imperial Weight Centre, Department of Investigative Medicine, Imperial College London, London W6 8RF, UK

Tel +442033I3 0532

Fax +442033I30673

Email c.leroux@imperial.ac.uk

\begin{abstract}
Obesity is an epidemic disease, and its prevalence is predicted to rise in the future. Many health and social comorbidities, such as cardiovascular disease, type 2 diabetes mellitus, cancer, nonalcoholic fatty liver disease, arthritis, infertility, eating disorders, unemployment, and low quality of life, have been associated with obesity. Nowadays, bariatric surgery is the only effective treatment for severe obesity. An increasing body of literature demonstrates significant remission of obesity-related comorbidities and an increase in life expectancy after surgical treatment. Unfortunately, serious complications can appear after surgery, and the careful preoperative assessment of patients is necessary to estimate the indications and contraindications of bariatric surgery. Recent studies report the lower complication and mortality rates when bariatric procedures are performed in high-volume centers. The purpose of this review is to describe the techniques of the currently used surgical procedures and the clinical effectiveness of bariatric surgery. Additionally, the possible complications and mortality rates after bariatric surgery are discussed.
\end{abstract}

Keywords: obesity, surgery, assessment, clinical effectiveness, complications

\section{Introduction}

The World Health Organization estimated that globally, in 2005, approximately 1.6-billion adults were overweight and at least 400 million were obese. ${ }^{1}$ Moreover, the prevalence of obesity is predicted to rise in the future. Unfortunately, obesity and overweight can have a variety of adverse health consequences associated with a high rate of death, such as type 2 diabetes mellitus (T2DM), dyslipidemia, hypertension, obstructive sleep apnea (OSA), certain types of cancer, steatohepatitis, gastroesophageal reflux, arthritis, polycystic ovary syndrome (PCOS), and infertility. ${ }^{2}$

Currently, bariatric surgery has become the only long-term effective treatment for severe obesity. ${ }^{3}$ Caloric restriction, diet, and drug therapy have disappointing results in the long-term weight loss for severe obesity. ${ }^{4,5}$ Patients who complete a comprehensive program providing a low-calorie or very low-calorie diet can expect to lose approximately $5 \%$ of the initial weight at 4 years, ${ }^{4}$ whereas patients receiving active pharmacologic treatments are more likely to achieve 5\%-10\% weight loss. ${ }^{5}$

In the Swedish Obese Subjects (SOS) study, a cohort study among patients with a body mass index $(\mathrm{BMI})>34 \mathrm{~kg} / \mathrm{m}^{2}$ followed for 10 years, the surgical group had a $16 \%$ weight loss compared with a $1.6 \%$ weight gain for patients receiving conventional treatment. ${ }^{3}$ Of note is the fact that the primary surgical procedure performed in a number of the operated patients was a vertical banded gastroplasty, a procedure no longer performed, and the fact the analysis was performed on an intention to treat basis. ${ }^{3}$ 
The three randomized controlled trials (RCTs) that compared bariatric surgery with non surgical treatments reported statistically greater mean percentage weight loss following bariatric surgery. ${ }^{6-8}$

The life expectancy of a severely obese person is reduced by an estimated 5-20 years. ${ }^{9}$ A large cohort prospective study and other retrospective cohort studies suggested that bariatric surgery reduces mortality considerably. In the SOS study, during a period of up to 15 years, the overall mortality was $30.7 \%$ lower among the bariatric group compared with control subjects, and the most common causes of death were myocardial infarction and cancer. ${ }^{10}$

In a large retrospective cohort study, during a mean follow-up of 7.1 years, adjusted long-term mortality from any cause in the surgery group decreased by $40 \%$ compared with the control group. The cause-specific mortality rate in the surgery group decreased by $56 \%$ for coronary artery disease, by $92 \%$ for diabetes, and by $60 \%$ for cancer. ${ }^{11}$ Moreover, Flum and Dellinger ${ }^{12}$ reported a 33\% reduction in the rate of death due to any cause after gastric bypass surgery as compared with the rate among control subjects after a mean follow-up of 4.4 years. Finally, Christou et al, ${ }^{13}$ at a mean follow-up of 2.6 years, reported that among patients who had undergone gastric bypass surgery, the rate of death due to any cause decreased by $89 \%$ compared with control subjects.

\section{Bariatric surgery today}

The most commonly performed bariatric procedures today are standard Roux-en-Y gastric bypass (RYGB), adjustable gastric banding (AGB), and sleeve gastrectomy (SG). ${ }^{14}$ A recent worldwide survey reported that over $90 \%$ of world bariatric surgery was performed laparoscopically. More specifically, laparoscopic AGB (LAGB) was performed in $42.3 \%$ worldwide, laparoscopic standard RYGB (LRYGB) in $39.7 \%$, open standard RYGB (ORYGB) in 5.7\%, and laparoscopic SG (LSG) in 5.1\%. ${ }^{14}$ Biliopancreatic diversion (BPD), as described by Scopinaro et al, ${ }^{15}$ was performed in $0.9 \%$ worldwide, and the BPD with duodenal switch (BPD-DS) was performed in $0.8 \% .{ }^{14}$ One of the contributing factors to these surgical procedures being less commonly performed is that they are technically more difficult than gastric bypass and are more prone to micronutrient and macronutrient deficiencies. BPD and BPD-DS might have a role in the treatment of extremely obese patients or in the treatment of patients who have failed to lose weight with the other bariatric procedures as they are effective procedures in weight loss and weight loss maintenance. ${ }^{16}$

\section{Bariatric surgery techniques in treating obesity}

The RYGB is the most common technique in United States. ${ }^{17}$ In RYGB, the stomach is divided into the upper stomach pouch, which is $15-30 \mathrm{~mL}$ in volume, and the lower stomach pouch, gastric remnant. The stomach pouch is then anastomosed to the jejunum, 30-75 cm distally to the ligament of Treitz, through a gastrojejunal anastomosis in a so called Roux-en-Y fashion. The continuity of the bowel is restored via a jejunojejunal anastomosis between the excluded biliary limb and the alimentary limb, performed at 75-100 cm distally from the gastrojejunostomy. ${ }^{18}$

LAGB involves the placing of an adjustable plastic and silicone ring around the proximal aspect of the stomach, immediately below the gastroesophageal junction creating a small proximal pouch. Currently, the most common technique of LAGB is "pars flaccida", which generally keeps the band above the apex of the lesser sac. Once in position, the band is tightened by closing the buckle and is secured with gastrogastric sutures to prevent band slippage or gastric herniation. A subcutaneous access port allows the degree of band constriction to be adjusted by the injection or withdrawal of a saline solution from the system. ${ }^{16,19}$

LSG is a new procedure gaining popularity, which originated as part of DS operation and later has been used as a first-stage procedure for super-obese and high-risk patients. In LSG, the stomach is transected vertically, creating a gastric tube and leaving a 150-200 mL pouch. The greater curve of the stomach is transected approximately $4-6 \mathrm{~cm}$ proximal to the pylorus, using a linear stapler. Once the bougie is inserted, all subsequent stapler firing is cephalad, parallel to the lesser curve and against the bougie until the angle of His. The remaining stomach is excised. ${ }^{20}$

BPD was developed by Scopinaro in late $1976 .{ }^{21}$ The technique of BPD includes a partial gastrectomy, leaving a $400-\mathrm{mL}$ gastric pouch. The small bowel is divided $250 \mathrm{~cm}$ proximally to the ileocecal valve, and the alimentary limb is connected to the gastric pouch to create a Roux-en-Y gastroenterostomy. An anastomosis is performed between the excluded biliopancreatic limb and the alimentary limb at $50 \mathrm{~cm}$ proximally to the ileocecal valve. ${ }^{16,22}$

DS is a variation of the BPD, first described by Hess and Hess. ${ }^{23}$ In this procedure, a vertical SG was constructed rather than subtotal gastrectomy, and the division of the duodenum is performed immediately beyond the pylorus. The alimentary limb is connected to the duodenum, whereas the biliopancreatic limb is anastomosed to the ileum $75 \mathrm{~cm}$ proximally to the ileocecal valve. ${ }^{16,22}$ 


\section{Preoperative assessment}

Although the overall mortality and morbidity rates of bariatric surgery are low, certain groups are at higher risk for complications because of the high prevalence of comorbidities. The King's College assessment criteria are now used in our unit for assessment of the presurgical bariatric patients (Table 1). ${ }^{24}$

The goals of the preoperative assessment for bariatric surgery are to assess indications and contraindications to bariatric surgery and to treat or improve medical comorbidities before the surgical treatment. Moreover, another aim is to educate the patients and their families about options and risks of the procedures and to set realistic expectations. ${ }^{25}$

\section{Clinical effectiveness}

\section{Airway and apnea}

Severe obesity can be associated with significant respiratory problems. The most important among them are OSA and asthma. Among severely obese patients presenting for bariatric surgery, $>70 \%$ meet the criteria for OSA. ${ }^{26,27}$ According to the American Academy of Sleep Medicine, OSA is said to be present when individuals experience in average at least 5 apneic or hypopneic events per hour (apneahypopnea index [AHI]). ${ }^{28}$ In 2004, a systematic review and meta-analysis reported improvements of sleep apnea in $85.7 \%$ and resolution in $83.6 \%$ after bariatric surgery. ${ }^{29} \mathrm{~A}$ recent meta-analysis in 2009 found that the mean AHI after surgical weight loss was consistent with moderately severe OSA and that patients undergoing bariatric surgery should not expect a cure for OSA after surgical weight loss but a significant improvement in OSA. ${ }^{28}$
Many studies demonstrate an association between obesity and asthma. ${ }^{30,31} \mathrm{BMI}$ has a strong, independent, and positive relation with asthma. ${ }^{32}$ Severely obese patients with asthma experience resolution or improvement after bariatric surgery. A large single-center study found that $26.1 \%$ of severely obese patients suffer from asthma before surgery, and the resolution after RYGB surgery was $66 \%{ }^{33}$ Several groups have reported major reduction in asthma severity after bariatric surgery-induced weight loss. ${ }^{33,34}$

\section{$\mathrm{BMI}$ and weight circumference}

The average weight loss after bariatric surgery is $20-40 \mathrm{~kg}$. 29,35 In the SOS study, the mean weight loss was $16.3 \%$ of the initial weight, and the average weight loss in 10 years was $19.9 \mathrm{~kg} .{ }^{3}$ After the mean weight loss reaches the maximum after 1-2 years, weight slowly increases for a decade before it stabilizes. ${ }^{3}$

After a period of 15 years in the SOS study, patients who had undergone LAGB and RYGB surgical procedures had lost $13 \% \pm 14 \%$ and $27 \% \pm 12 \%$ of their total body weight, respectively. ${ }^{10}$ For SG, a systematic review demonstrated a $14 \mathrm{~kg} / \mathrm{m}^{2}$ reduction in BMI. ${ }^{36}$

Few RCTs have compared the weight loss between surgical procedures. In one of them, SG seems to achieve the same weight loss as RYGB at 1-year follow-up. ${ }^{37}$ Furthermore, Himpens et $\mathrm{al}^{38}$ comparing LSG and LAGB at 1-year and 3-year follow-up found that SG achieves significantly greater weight loss and reduction in BMI. On the other hand, Angrisani et al ${ }^{39}$ showed in a RCT that the mean weight was significantly better in the LRYGB than in the LAGB after 5 -year follow-up.

Table I The summarization of Modified King's criteria ${ }^{24}$

\begin{tabular}{|c|c|c|c|c|}
\hline & Stage 0 & Stage I & Stage 2 & Stage 3 \\
\hline Airway & Normal & Snoring & Sleep apnea require CPAP & Cor pulmonale \\
\hline BMI & $<30$ & $30-35$ & $35-50$ & $>50$ \\
\hline Cardiovascular & $<25 \%$ risk & $>25 \%$ risk & Heart disease & Heart failure \\
\hline Diabetes & Normal & Impaired fasting glycemia & Type 2 diabetes & Uncontrolled type 2 diabetes \\
\hline Economic & Normal & Suffered discrimination & Unemployed due to obesity & Requires financial support \\
\hline Functional & $\begin{array}{l}\text { Can manage } 3 \\
\text { flights of stairs }\end{array}$ & $\begin{array}{l}\text { Manage I or } 2 \text { flights } \\
\text { of stairs }\end{array}$ & $\begin{array}{l}\text { Manage }<\text { I flight of stairs or requires } \\
\text { walking aids }\end{array}$ & House bound \\
\hline Gonadal & Normal & Irregular periods & PCOS/impotence & Infertility \\
\hline Health status & Normal & Low mood or QoL & Moderate depression or poor QoL & Severe depression \\
\hline Image & Normal & $\begin{array}{l}\text { Does not like looking } \\
\text { in mirror }\end{array}$ & Avoids mirrors/body image dysphoria & Severe eating disorder \\
\hline Junction gastroesophagus & Normal & Heart burn & Esophagitis & Barrett esophagus \\
\hline Kidney & Normal & Proteinuria & $\mathrm{GFR}<60 \mathrm{~mL} / \mathrm{min}$ & $\mathrm{GFR}<30 \mathrm{~mL} / \mathrm{min}$ \\
\hline Liver & Normal & Raised LFT/NAFLD & $\mathrm{NASH}$ & Liver failure \\
\hline
\end{tabular}

Abbreviations: CPAP, continuous positive airway pressure; BMI, body mass index; PCOS, polycystic ovary syndrome; QoL, quality of life; GFR, glomerular filtration rate; LFT, liver function test; NAFLD, nonalcoholic fatty liver disease; NASH, nonalcoholic steatohepatitis. 


\section{Cardiovascular disease}

Severe obesity increases the frequency and the severity of the metabolic syndrome, which is the major risk factor for cardiovascular disease. ${ }^{40}$ Its prevalence in obese patients was nearly 10 -fold higher compared with nonobese patients. ${ }^{41}$ The definition of metabolic syndrome includes the coexistence of any three of the following five features: central obesity, high serum triglyceride levels, low serum high-density lipoprotein (HDL)-cholesterol levels, hypertension, and elevated fasting blood glucose levels.

Buchwald et $\mathrm{al}^{29}$ reported a $61.7 \%$ improvement of hypertension, $70 \%$ improvement of hyperlipidemia, and $86 \%$ resolution of diabetes in obese patients undergoing surgery. On the other hand, in the SOS study, the 10-year resolution rates of blood triglycerides, diabetes, and diastolic blood pressure remained favorable at 10 years after surgery, whereas systolic blood pressure and HDL levels were only improved at 2 years after surgery. ${ }^{3}$

Bariatric surgery also delays the progression of atherosclerotic disease. In a 4-year controlled interventional study of carotid artery atherosclerosis, obese patients treated with surgery had a threefold lower rate of progression compared with controls. ${ }^{42}$ It is noteworthy that two large retrospective studies show reduced long-term mortality of cardiovascular diseases. Adams et a ${ }^{11}$ found that the cause-specific mortality in the surgery group decreased by $56 \%$ for coronary artery disease, and Christou et al ${ }^{13}$ reported that the risk of cardiovascular disease in the surgery group decreased by $72 \%$.

Moreover, the severity and the duration of obesity are associated with changes in cardiac structure and function. ${ }^{43}$ The most frequent abnormalities are the increased cardiac mass, the left ventricular hypertrophy, and the abnormal measures of diastolic left ventricular function. ${ }^{44,45}$ Bariatric surgery has been demonstrated as a successful modality to improve left ventricular hypertrophy and systolic and diastolic performance. ${ }^{45-47}$

\section{Diabetes}

Obesity and T2DM are likely to be some of the greatest public health problems in the world. There is a strong relationship between the Obesity and T2DM, and the term "diabesity" has been coined to suggest an overlap of the both. ${ }^{48,49}$ Approximately, half of the patients diagnosed with T2DM are obese and $20 \%-30 \%$ of those who underwent bariatric surgery are with diabetes. ${ }^{50,51}$

A recent meta-analysis demonstrates that bariatric surgery has impressive results in the treatment of diabetes, although the criteria used to define remission may now be outdated, and stricter criteria will result in much lower rates of remission. ${ }^{52}$ However, the meta-analysis showed that $78.1 \%$ of diabetic patients had complete remission and $86.6 \%$ had improvement or remission of diabetes after bariatric surgery ${ }^{53}$ Regarding the effectiveness of each procedure, diabetes remission is greatest for patients undergoing BPD-DS, followed by gastric bypass, and least for gastric banding. In the surgically treated group of SOS study, T2DM had resolved in $72 \%$ after 2 years, but unfortunately, only $36 \%$ of those who had diabetes at the baseline remained free of the disorder at 10 years. ${ }^{3}$ In a RCT, Dixon et $\mathrm{al}^{6}$ compared the effectiveness of LAGB and conventional therapy in remission of T2DM at 2 years of follow-up and found that it was significantly higher (73\%) in the LAGB group compared with the conventional group (13\%). Generally, bypass procedures produce the highest and most rapid rates of T2DM remission and are thought to occur by a weight loss-independent mechanism that may involve the role of gut hormones through the so called enteroinsular axis. ${ }^{47,54}$

Finally, it is noteworthy that Adams et $\mathrm{al}^{11}$ in a large cohort study described a remarkable $92 \%$ decrease in diabetes-related deaths after RYGB surgery.

\section{Economic complications}

The major economic complications for obese patients are unemployment, reduced productivity, and the comorbidityrelated cost of care. The social stigma associated with being overweight may limit a person's ability to get a job..$^{55}$ The majority of studies investigating occupational status showed an increase in employment after surgery. ${ }^{56}$ Productivity has also been shown to increase significantly after bariatric surgery, with fewer days on sick leave..$^{56-58}$ The SOS study showed that the number of days lost owing to sick leave before the surgery was twice as high as in the general Swedish population, and the disability pension was also twice as frequent as in the general Swedish population. During the first year after treatment, the surgically treated group had $35 \%$ more days of sick leave compared with the controls but significantly fewer days during the second and third year. During the years 4-5, the difference in sick leave between groups was not significant. ${ }^{58}$

In the SOS study, the medication cost increased in both the surgical and the conventional groups over the 6-year period, and there was no significant difference in total pharmaceutical cost between the groups. ${ }^{59}$ Average drug-specific costs were different between groups though. The surgically treated group had lower medication costs for diabetes and cardiovascular disease but higher medication costs for anemia 
and gastrointestinal disorder as compared with the conventionally treated group. ${ }^{59}$

Moreover, in a study on the economic impact of bariatric surgery, the costs of open surgery are fully recovered after 4 years and that of laparoscopic bariatric surgery are fully recovered after 2 years. The cost reductions observed in this analysis mirror the comorbidity reductions in diseases associated with obesity in terms of prescription drug use, hospital visits, and physician visits. ${ }^{60}$

\section{Functional (physical functioning)}

Severely obese individuals experience significant impairment in activities of daily living such as walking, climbing stairs, and bathing. ${ }^{61}$ These are reported to be the most distressing aspects of their obesity. ${ }^{61}$ Furthermore, obese and overweight individuals face an increased risk of musculoskeletal pain and osteoarthritis. ${ }^{62}$

O'Brien et $\mathrm{al}^{8}$ in a RCT found that physical functioning scores of obese patients who underwent LAGB surgery improved significantly better compared with medically treated patients. Moreover, the SOS study reports that patients who underwent bariatric surgery reported significant improvement (or resolution) in types of "work-restricting" pain in the neck, back, hips, knees, and ankles. ${ }^{62}$ In a prospective study, McGoey et $\mathrm{l}^{63}$ found that after a mean surgical weight loss of $44 \mathrm{~kg}$, the prevalence of back pain decreased from $62 \%$ to $11 \%$, hip pain from $11 \%$ to $2 \%$, knee pain from $57 \%$ to $14 \%$, ankle pain from $34 \%$ to $2 \%$, and foot pain from $21 \%$ to $1 \%$. On the other hand, Melissas et $\mathrm{al}^{64}$ reported a significant improvement in the low back pain after bariatric surgery even though the patients were still obese with a BMI of $34 \mathrm{~kg} /$ $\mathrm{m}^{2}$ at the end of the study.

\section{Gonadal}

Obesity is associated with infertility. ${ }^{65}$ In a large, prospective, multicenter study, $41.9 \%$ of women undergoing bariatric surgery experienced subfertility, but $61.4 \%$ had a live birth after surgery. ${ }^{66}$ The mechanisms contributing to subfertility in this cohort may include androgen excess, insulin resistance, and hyperinsulinism. Many studies found evidence of improvement in fertility after bariatric surgery via the normalization of hormones and menstrual cycles and the reduction of PCOS. ${ }^{67-70}$

PCOS is a syndrome characterized by infertility, menstrual dysfunction, hyperandrogenemia, and hyperinsulinemia. In the longitudinal assessment of bariatric surgery (LABS) study, PCOS was diagnosed in $13.1 \%$ of women undergoing bariatric surgery, a rate significantly higher compared with that of the general population. ${ }^{66}$ In a prospective study of 12 women with PCOS after bariatric surgery, all had improvements in hirsutism, hyperandrogenemia, insulin resistance, and restoration of regular menstrual cycles and/or ovulation. ${ }^{70}$ In another retrospective study of 24 women who had PCOS and gastric bypass, all had complete resolution of their menstrual irregularity, and those who wanted to be pregnant were able to do so without the need for clomiphene, whereas $75 \%$ had marked improvement in a hirsutism score. ${ }^{71}$

A number of studies have shown that maternal obesity introduces multiple risks for the mother and the fetus during pregnancy. ${ }^{72,73}$ According to the American College of Obstetrics and Gynecology, all bariatric surgery patients are advised to delay pregnancy during the rapid weight loss phase within the first $12-18$ months after surgery. ${ }^{74}$ A systematic review of maternal and neonatal complications suggests that the risk for maternal complications, such as gestational diabetes and preeclampsia, may be lower following surgically induced weight loss than the risk in obese women and may approach nonobese population rates. Similarly, neonatal complications, such as premature delivery and low birth weight, may be lower in pregnancies following bariatric surgery. ${ }^{75}$

Obesity is also associated with high risk of sexual dysfunction. ${ }^{74}$ Many patients present for bariatric surgery with the expectation that weight loss will improve their sexual relations with their partner, and most patients indicate a significant improvement and a more satisfying sexual life after surgery. ${ }^{56}$

\section{Health status perceived}

Previous research has demonstrated that $25 \%-30 \%$ of patients had marked clinical symptoms of depression before surgery. ${ }^{61}$ The SOS study provides the best available evaluation of changes in overall mood, depression, and anxiety after bariatric surgery. Poor general health perceptions have frequently been associated with limitations in functional ability, physical and mental symptoms, and a number of medical diagnoses. ${ }^{76}$ In the SOS study, health perceptions improved by $11 \%$ after 10 years. The significant improvement from baseline to 10-year follow-up is in line with the positive long-term effects of weight reduction but was significantly lower than the population norm. ${ }^{76}$

In the overall mood, powerful improvements were observed in the surgical group during the first year after bariatric surgery. However, the effect on overall mood after 10 years was positive in patients with weight losses of $10 \%$ or more, whereas no improvement was observed in patients who lost less than $10 \%$ of their initial weight. ${ }^{76}$ 
The depression scores decreased to about $27 \%$ at 10 -year follow-up. Depression was improved at 10-year follow-up, but the prevalence was still higher than the population norm. A substantial reduction of anxiety symptoms (23\%) was seen in the surgical group 10 years after surgery.

Severe obesity is associated with multiple forms of negative health impact that affects quality of life. In the SOS study, the change in the health-related quality of life (HRQL) during the 10-year observation period largely followed phases of weight loss, weight regain, and weight stability. In the surgical group, the peak HRQL improvements were observed during the first year of weight loss. They were followed by a gradual decline between 1 and 6 years, and then observations were relatively stable between 6- and 10-year follow-up. At 10 years, net gain was noted in all HRQL domains compared with baseline. Long-term results of the study suggest that a maintained weight loss of $10 \%$ is sufficient for positive long-term effects on HRQL. This limit was reached in about two-third of the surgically treated patients who completed the 10 years of the study. The authors concluded that the long-lasting weight reduction after bariatric surgery has a general long-standing positive outcome on HRQL. ${ }^{76}$

In another recent comparison of gastric bypass surgery with severely obese patients who did not undergo surgery, gastric bypass led to improved HRQL. ${ }^{77}$ A systematic review concluded that in the majority of bariatric patients at follow-up there are significant improvements of quality of life. ${ }^{56}$ A RCT comparing LAGB and conventional therapy reports that at 2 years, the nonsurgical group had statistically significant improvements in some HRQL domains. However, the surgical group had statistically significant improvements in all HRQL domains. ${ }^{8}$

\section{Body image}

Commonly, overweight and obese individuals suffer from body image dysphoria. ${ }^{61}$ Several studies have reported the association between weight loss after bariatric surgery and improvement in body image. Adami et $\mathrm{al}^{78}$ reported that 3 years after the surgery, the scores of patients on body image dissatisfaction subscale were dramatically improved and were similar to the scores observed in normal-weight individuals. The great majority of studies indicated a considerable improvement of self-esteem after surgery. ${ }^{56}$

In addition, in the SOS study, health-related limitations in social interaction (SI) within the family, among friends, and in the community were evaluated. A small treatment effect on SI was noted for surgical subjects who lost $10 \%$ or more of their body weight, whereas no change was seen in surgical subjects who lost $<10 \%$ of their initial weight. ${ }^{76}$

Eating disorders are common in patients undergoing bariatric surgery. Approximately $10 \%-25 \%$ of patients meet the criteria for binge eating disorder (BED), whereas the prevalence of night eating syndrome (NES) is between 5\% and 20\%. ${ }^{61}$ BED involves repeated uncontrolled episodes during which objectively large amounts of food are consumed in association with marked emotional disturbance. Several studies have investigated the relationship between the presence of BED before surgery and the postoperative weight loss, but the results are contradictory. ${ }^{79,80}$ There is evidence that RYGB may improve eating-disordered behavior. Hsu et $a{ }^{81}$ reported that none of the patients who had BED before surgery reported BED after RYGB surgery. In another study of LAGB, preoperative BED, uncontrolled eating, and NES occurred in $14 \%, 31 \%$, and $17.1 \%$ of subjects. These eating disorders were reduced after surgery to $3.1 \%, 22.5 \%$, and $7.8 \%$, respectively. ${ }^{82}$ Having active BED after the surgery may be a poor prognostic feature, and hence, treatment should be considered before the surgery. ${ }^{83}$

\section{Junction of gastroesophagus}

Gastroesophageal reflux disease (GERD) has been shown to have a strong association with BMI ${ }^{84}$ Central adiposity may be the most important risk factor for the development of reflux and related complications such as Barrett esophagus and esophageal adenocarcinoma. ${ }^{85,86}$ RYGB seems to be a beneficial surgical treatment for GERD in obese patients, as the small stomach pouch reduces acid production and limits reflux. In a prospective study, GERD symptoms decreased in $94 \%$ of patients at 9 months after surgery. ${ }^{87}$ Similarly, in another study, the resolution of GERD after RYGB surgery was $87.6 \%{ }^{33}$ Frezza et al ${ }^{88}$ prospectively examined the effect of RYGB surgery in 152 severely obese patients with chronic GERD. Approximately $80 \%$ of patients had GERD symptom resolution at the 6-month follow-up.

LAGB is another option for the treatment of obesity and GERD symptoms. Dixon and O'Brien ${ }^{89}$ demonstrated resolution of all reflux symptoms occurred in $76 \%$ and improvement in another $14 \%$ of patients undergoing LAGB surgery. Himpens et al, ${ }^{38}$ in a RCT comparing patients who received SG and LAGB surgery, noted the disappearance of GERD in $83.3 \%$ and $75 \%$ of patients after LAGB surgery and $\mathrm{SG}$, respectively.

Despite the proposed benefit of banding in reflux, other studies have shown contradictory results and worsening of reflux symptoms after LAGB surgery. ${ }^{90} \mathrm{~A}$ recent systematic 
review revealed that although LAGB surgery often leads to improvement or even resolution of reflux symptoms in the short term, worsening or newly developed reflux symptoms and esophagitis were reported in a subset of patients when longer follow-up was available. ${ }^{91}$ Further well-designed studies with long follow-up are needed to establish the effect of banding on this disease. SG may also cause reflux by decreasing the pressure in the lower esophageal sphincter. ${ }^{92,93}$

Csendes et $\mathrm{al}^{94}$ reported that in obese patients, the incidence of Barrett esophagitis before surgery was 2.1\%. After RYGB surgery, symptoms of reflux disease, signs of erosive esophagitis, and peptic ulcer disease were no longer present. ${ }^{94}$ Additionally, Houghton et $\mathrm{al}^{95}$ in their study of five patients with Barrett esophagitis before surgery reported complete or partial regression of Barrett esophagitis after RYGB surgery in four patients and improvement in reflux symptoms in all.

\section{Kidney}

Obesity is associated with impaired renal parameters, obesity-related glomerulopathy, and chronic kidney disease (CKD). ${ }^{96}$ In the Framingham study, obese patients who were initially free of CKD were likely to reduce their glomerular filtration rate (GFR) over time. ${ }^{97}$ However, in a study of 61 patients, renal parameters and renal function were markedly improved 24 months after bariatric surgery. ${ }^{98}$ The earliest marker of CKD risk is microalbuminuria and is associated with risks of progression to end-stage CKD. A recent metaanalysis found that weight loss is associated with decreased proteinuria and microalbuminuria. ${ }^{99}$ The literature is incomplete, but a case series describe improvements or stability of CKD and improved outcomes in renal transplant patients after obesity surgery. ${ }^{100}$ In a retrospective study including 25 patients with chronic renal disease, the mean GFR increased significantly at 12 months after undergoing bariatric surgery than before surgery. ${ }^{101}$ However, the measurement of GFR with the modification of diet in renal disease equation may give inaccurate results as the routine equation does not take weight into consideration.

\section{Liver}

Nonalcoholic fatty liver disease (NAFLD) includes a wide spectrum of liver disease from hepatic steatosis, nonalcoholic steatohepatitis (NASH), fibrosis, and cirrhosis. In a review of obese patients undergoing bariatric surgery, the prevalence of steatosis, NASH, and unexpected cirrhosis was $91 \%, 37 \%$, and $1.7 \%$, respectively. ${ }^{102}$ Obesity and insulin resistance are considered to be the main causative factors of NAFLD. ${ }^{103}$ Several studies on severely obese patients with NAFLD have shown an improvement in liver disease after bariatric surgery. Dixon et al ${ }^{104}$ studied 36 severely obese patients with NAFLD who underwent LAGB surgery, comparing liver biopsies at a mean 2-year follow-up, and showed significant improvements in steatosis, fibrosis, and necroinflammatory scores. After RYGB surgery, Mottin et al ${ }^{105}$ demonstrated that liver steatosis before surgery was $87.6 \%$, but 12 months after the surgery, only $17.8 \%$ of the patients had the same degree of steatosis, $27.8 \%$ improved their steatosis pattern, and $54.4 \%$ had normal hepatic tissue. In a meta-analysis on the effect of bariatric surgery on NAFLD, the patients with improvement in or resolution of steatosis, steatohepatitis, and fibrosis were 91.6\%, 81.3\%, and $65.5 \%$, respectively, and the patients with complete resolution of NASH were $69.3 \% .^{106}$

\section{Medication}

Obesity and its comorbidities are associated with increased prescription drug use. ${ }^{107}$ In the SOS study, $52 \%$ of the obese individuals were taking medications compared with only $36 \%$ of the randomly selected reference population. ${ }^{59}$ The obese patients in this study were more often taking medication for cardiovascular disease, pain, psychiatric disorders, diabetes mellitus, and asthma. In the SOS study, of the obese individuals in the surgical group taking any medications at baseline, only $76.7 \%$ were still taking medications 6 years after the surgery. ${ }^{59}$

In $\mathrm{RYGB}$, a large study reported that the average use of medications reduced from 4.4 per patient before surgery to 1.3 per patient after surgery. ${ }^{33}$ Similarly, in another study, the mean number of medications for the treatment of hypertension, hyperlipidemia, GERD, and T2DM in 77 patients decreased from 2.4 before surgery to 0.2 per patient 12 months after RYGB surgery. ${ }^{108}$ Furthermore, Ahroni et al ${ }^{109}$ demonstrated that after LAGB surgery the use of medication declined significantly.

\section{Nutrition}

Bariatric surgery is related to changes in eating behavior. In a RCT, Olbers et $\mathrm{al}^{110}$ showed that patients after RYGB surgery have a decreased preference for sugary and fatty foods, whereas they increase their preference for vegetables. The SOS study also reports the dramatic changes at eating behavior in the surgical group 6 months after the operation and also at 2-year follow-up despite a small reduction in the primarily effectiveness. The restrained eating substantially increased, and the disinhibition and hunger significantly decreased. ${ }^{111}$ 


\section{Other complications}

\section{Cancer}

Cancer incidence is increased in obese individuals. A recent meta-analysis shows that high BMI is associated with an increased incidence of many types of cancer. ${ }^{112}$ Certain recent studies support that bariatric surgery is associated with a reduction in the overall cancer incidence. In the prospective SOS cohort study, the number of first time cancers after inclusion was lower in the surgery group than in the control group. Moreover, the SOS study concluded that bariatric surgery had a significant effect on cancer incidence in women but not in men. ${ }^{13}$

In two retrospective cohort studies of obese patients treated with bariatric surgery, there was also a reduction in cancer incidence in patients who underwent bariatric surgery compared with those who did not. Adams et al ${ }^{11}$ found that mortality in the surgery group decreased by $60 \%$ for cancer during a mean follow-up of 7.1 years, and Christou et al ${ }^{114}$ after a 5-year follow-up, found that the postbariatric surgery group has significantly fewer visits to the physician or hospital for "all cancer" diagnosis compared with the nonoperated, severely obese control group. There were only $2 \%$ reported bariatric surgery patients with cancer compared with $8.5 \%$ control subjects. ${ }^{114} \mathrm{~A}$ recent retrospective focusing on breast and endometrial cancer incidences showed that bariatric surgery may decrease cancer development. ${ }^{15}$

\section{Surgical complications}

A meta-analysis of total surgical mortality in 85,048 patients undergoing a spectrum of bariatric procedures reports that the early total mortality ( $<30$ days) was $0.28 \%$, whereas the late total mortality ( $>30$ days and $<2$ years) was $0.35 \%$. More specifically, early mortality rate for LAGB, LRYGB, and ORYGB was $0.06 \%, 0.16 \%$ and $0.44 \%$, respectively. ${ }^{116}$ In another systematic review, the mortality rate at the first 30 days for SG was $0.19 \%{ }^{36}$ A multicenter study of high volume centers in United States demonstrates that the rate of death was $0.3 \%$ at 30 days, similar to the mortality rates after laparoscopic cholecystectomy. ${ }^{117}$ Additionally, Adams et $\mathrm{al}^{11}$ in their large cohort study showed similar mortality rate $(0.53 \%)$ between bypass surgery and medical treatment in patients at 12 months. Male gender, older age, high BMI, significant comorbidities, and surgeon's experience have been identified as predictors of adverse effects. ${ }^{118}$ Recently, DeMaria et $\mathrm{al}^{119}$ developed a simple, clinically relevant 5 -point scoring system, the obesity surgery mortality risk score, assigning 1 point to each of five preoperative variables, including BMI $>50 \mathrm{~kg} / \mathrm{m}^{2}$, male gender, hypertension, age $>45$ years, and the known risk factor for pulmonary embolus. With the aid of this tool, the mortality risk of patients is defined as low $(0-1 p)$, intermediate $(2-3 p)$ and high risk (4-5p). Certainly, the training and the bariatric surgeon's experience are important factors that must be improved for the benefit of the patient. In a recent study, the overall complication and hospital mortality in patients who underwent gastric bypass surgery were analyzed to estimate the relationship between surgeons' and hospitals' volume per year and the incidence of complications and mortality. The results of this study demonstrated an inverse relationship between the surgeon and hospital procedure volume and the in-hospital complications and mortality. ${ }^{120}$ The future trend for bariatric surgery is to be performed at Centers of Excellence (COE). These centers have an established record of good technique, experienced surgeons, a comprehensive team approach, and acceptable outcomes. ${ }^{121}$ In the United States, bariatric surgery is currently performed safely in COE with an all-cause mortality rate of $0.09 \%$ and $0.11 \%$ at 30 and 90 days, respectively, whereas the complication rate in 57,918 procedures was approximately $17 \%{ }^{122}$ This study supports a progressive decline in bariatric surgery mortality in recent years. A recent study from Michigan reported a complication rate of $3.6 \%$ for gastric bypass, $2.2 \%$; for SG and $0.9 \%$ for gastric banding. ${ }^{123}$ Interestingly, the complication rate was inversely related to centre and surgeon volume of operations, but there was no association with $\mathrm{COE}$ status. ${ }^{123}$

Finally, in the LABS study, a total of $4.3 \%$ of patients had at least one major adverse outcome during the first 30 days after the surgery, such as the composite end point of death, deepvein thrombosis, or venous thromboembolism, reintervention, or failure to be discharged by 30 days after surgery. ${ }^{117}$

\section{Early surgical morbidity}

Early perioperative morbidity is defined as the complication that occurs within the first 30 days after the surgery, whereas late complications are those that occur $>30$ days before surgery and nutritional deficiencies.

Patients with severe venous disease are at high risk for perioperative venous thromboembolism, and the incidence of venous thromboembolism is reported to be between $0.4 \%$ and $3.1 \%$, and the rate of pulmonary embolism ranges from $0 \%$ to $1.1 \%$ for RYGB. ${ }^{124,125}$ Podnos et al ${ }^{126}$ found no difference in postoperative pulmonary embolism between laparoscopic and open gastric bypass. The risk for deep-vein thrombosis or pulmonary embolism after LAGB surgery is lower than for other bariatric procedures. ${ }^{125}$ Furthermore, wound infection is a common complication 
associated mainly with open bariatric surgery, whereas laparoscopic bariatric procedures have low wound infection rates. $^{126}$

Early perioperative complications for RYGB include postoperative anastomotic leak, bowel obstruction, and hemorrhage. Anastomotic leak mainly at the gastrojejunostomy but also at the jejunojejunostomy are perhaps the most feared complications of gastric bypass surgery. The leak rate has been reported to be about $0.5 \%-4.4 \%$ after RYGB surgery. ${ }^{124,125}$ The early signs of a leak are tachycardia and abdominal pain. A delay in the diagnosis may lead to peritonitis, overwhelming sepsis, and death. A high index of suspicion is crucial for the early recognition of an anastomotic leak. The radiological investigations are often not helpful. If the patients' clinical picture accord with leak, then immediate intervention with laparoscopy is needed. Another complication of RYGB is the postoperative bowel obstruction, which occurs early or late after the RYGB surgery, and its incidence ranged from $0.4 \%$ to $5.5 \% .{ }^{127}$ Finally, bleeding occurs in $0.4 \%-4 \%$ of patients. ${ }^{124}$ Postoperative bleeding can be intraperitoneal from mesenteric or omental vessels and intraluminal from the anastomosis or the staple line.

The early complications of LAGB placement consist of gastric perforation, stoma obstruction, and infection at access port. Gastric or esophageal perforation is a serious complication that may occur several days after surgery with signs and symptoms of tachycardia, hypotension, fever, and abdominal pain. ${ }^{127}$

Stoma obstruction after LAGB surgery is presented in a rate of $0.2 \%-1.6 \% .{ }^{127}$ With the introduction of larger bands, the complication of postoperative obstruction has become less common. Infections of the adjustment port can be early or late, and the distinction between the late and early infections is important because the etiology is different. An immediate postoperative infection of the port should be treated with antibiotics, whereas an infection outside the perioperative timeframe is attributed to erosion until proven otherwise. ${ }^{121}$

The early complications of SG include leak, hemorrhage of the suture line, and stricture of the sleeve. When the SG is the primary procedure for weight loss, the leak rate is approximately $2.7 \%$, the bleeding rate $1.0 \%$, and the stricture rates $0.5 \%{ }^{36}$ Leaks are potentially lethal. The current trend in the treatment of leaks after SG is the use of endoscopically placed stents, which are removed 6-8 weeks later. ${ }^{128}$ These stents can provide rapid healing and earlier return to enteral nutrition, but unfortunately, the incidence of migration remains relatively high, and more clinical studies are required to outline the risks and benefits. ${ }^{129}$

\section{Early gastrointestinal and nutritional complications}

Vomiting frequently occurs during the first few months after surgery but should always be considered as pathological. Vomiting typically happens 1-3 times a week and may be due to eating too quickly, overeating, or not chewing the food adequately. Special care should be taken to prevent dehydration, hypokalemia, hypomagnesemia, and thiamine deficiency. The supplementation of all these micronutrients and electrolytes is necessary if vomiting persists. ${ }^{130}$

\section{Late surgical complications}

Late surgical complications for RYGB include anastomotic stricture, bowel obstruction, and incisional hernia. The late postoperative bowel obstruction can result from adhesions or internal hernias. The internal hernias are more common after LRYGB than ORYGB surgery, and their incidence in LRYGB is nearly $2.5 \% .{ }^{131}$ There are potential internal hernia spaces, the number of which depends on the technique used. Iannelli et al ${ }^{131}$ in a review of approximately 11,000 patients undergoing LRYGB surgery recommended the closure of mesenteric defects with nonabsorbable running suture. Patients with bowel obstruction present with abdominal pain, nausea, and vomiting. Another common complication of RYGB, the anastomotic stricture, is found in $0.5 \%-4.9 \%$ of patients. ${ }^{127}$ Vomiting, nausea, and epigastric discomfort occurring immediately after every meal are the first signs of stricture, which are first noted 4-6 weeks after surgery. In addition, the patients with anastomotic stricture present with dysphagia to solids greater than liquids.

The incisional hernias are more common after open surgery but can occur after LRYGB surgery at the large port sites. ${ }^{126}$ The late surgical complications of LAGB include band slippage, band erosion, access-port infection, and port and tubing problems. Band slippage occurs in 2.3\%-12.3\% of patients after LAGB surgery. ${ }^{127}$ Nausea, vomiting, and heartburn after meals along with failure to lose weight are the most frequent symptoms of this complication. An upper gastrointestinal contrast study is the most commonly used diagnostic test to detect band slippage. The technique of LAGB positioning plays an important role in the incidence of slippage. ${ }^{132}$ In a RCT, O'Brien et $\mathrm{al}^{19}$ demonstrated that the pars flaccida technique is significantly less likely to be associated with slippage compared with perigastric technique.

Erosion is another infrequent late complication, and its incidence is $0.1 \%-2.8 \%{ }^{127}$ An eroded band usually occurs years after implantation and presents with abdominal pain, weight regain, loss of sense of restriction, and port-site infection. Band erosion rates are associated with surgeon's 
experience. O'Brien and Dixon ${ }^{133}$ in a large series reported that gastric prolapse occurred in $25 \%$ and erosion occurred in $3 \%$ of the first 500 patients, whereas in the last 600 patients, prolapse occurred in $4.7 \%$ and no erosion occurred.

Port-site infection is a rare late complication that appears in $0.4 \%-1.0 \%$ of patients after LAGB surgery. ${ }^{127}$ Erythema, induration, and drainage at the port site are the main signs of port-site infection. Other problems with the adjustment port include the leakage and the inaccessibility.

Chapman et $\mathrm{al}^{134}$ in a systematic review reported that tube or port malfunction requiring reoperation occurs in $1.7 \%$ of cases, whereas overall complications requiring reoperation occur in up to $18 \%$ of patients for LAGB.

\section{Late gastrointestinal complications}

Rapid weight loss with or without surgery is commonly associated with cholelithiasis. The incidence of gallstones after bariatric surgery varies between $22 \%$ and $71 \%$. ${ }^{124}$ Some clinicians advocate the use of ursodiol for at least 6 months after surgery in an attempt to reduce the incidence of gallstone formation, although the literature is controversial. ${ }^{135,136}$ Vomiting may occur during the first few months after surgery in all bariatric procedures but mainly in LAGB. Vomiting can be a signal of problems associated with strictures and stoma stenosis. Constipation is common after RYGB, AGB, and SG surgical procedures, whereas diarrhea can occur less frequently after RYGB surgery.

Dumping syndrome occurs in up to $14.6 \%$ of patients after RYGB surgery. ${ }^{137}$ Patients will often complain about a very uncomfortable feeling after eating a high glucose meal. Symptoms include watery diarrhea, nausea, bloating, and abdominal cramping.

Another late gastrointestinal complication for RYGB is marginal ulceration. It occurs at the gastrojejunal anastomosis and presents with symptoms that include vague abdominal pain, nausea, vomiting, and hemorrhage. Marginal ulcers at the anastomosis between the stomach pouch and the small intestine are a common cause of blood loss.

Finally, GERD also appears after LAGB surgery and SG. Patients complain of heartburn after their meals. Himpens et $\mathrm{al}^{38}$ showed that the incidence of de novo GERD after SG is $21.8 \%$ at 1 -year follow-up with subjective improvement of the symptoms $(3.1 \%)$ at 3-year follow-up. In contrast, they reported that after LAGB surgery, GERD appeared de novo in $8.8 \%$ of patients at 1 year and in $20.5 \%$ at 3 years. In another long-term study examining patients 5 years after LAGB surgery, despite significant weight loss, the incidence of gastroesophageal reflux and esophagitis was $44 \% .^{90}$

\section{Late nutritional and metabolic complications}

Deficiencies in micronutrients after bariatric surgery are associated primarily with RYGB, but they are also reported in LAGB and SG. Deficiencies of iron (in menstruating women), vitamin $B_{12}$, folate, calcium, and fat-soluble vitamins (A, D, E, and K) are common after gastric bypass surgery. Moreover, secondary hyperparathyroidism and problems with bone mineralization due to vitamin $\mathrm{D}$ deficiency and the already reduced ability to absorb calcium have been reported by several groups after gastric bypass surgery. ${ }^{130}$ LAGB may lead to nutrient deficiencies as a result of frequent vomiting. Excessive vomiting can cause neuropathies after LAGB surgery mainly because of thiamine deficiency. ${ }^{138}$ In a recent study, Gehrer et $\mathrm{al}^{139}$ found that most frequent postoperative deficiencies after LSG were zinc, vitamin D, folic acid, iron, and vitamin $B_{12}$. Patients with persistent low iron levels should be evaluated for blood loss through the gastrointestinal tract. The monitoring and the early supplementation of the vitamins are the best forms for preventing these complications.

Diversional procedures often have severe problems related to protein and fat malabsorption, especially if the Roux limb is very long. Protein deficiency and fat malabsorption can be identified earlier by observing the trend of albumin and fat-soluble vitamins.

A newly recognized complication after gastric bypass surgery is the hyperinsulinemic hypoglycemia with or without nesidioblastosis. The exact causative factor for the nesidioblastosis is unknown but might be related to a change in concentrations and activity of gut hormones due to the change in the upper gastrointestinal tract. Symptoms occur postprandially and include palpitations, tremor, sweating, anxiety, and hunger. ${ }^{140}$

Another frequent complication which can be terribly distressing to the patient is the hair loss. Although there is no known treatment, it usually reverses without intervention while the weight of the patient stabilizes.

\section{Failure of weight loss}

One of the most problematic issues is not meeting the patients' expectation, as regards with weight loss, with the information given before surgery. Reoperations are technically more difficult than primary procedures and have high perioperative complication rates with inferior outcomes. In the SOS study among 1,338 subjects who were followed for at least 10 years, the frequency of reoperation or conversion surgery was $31 \%$ for gastric banding and $17 \%$ for gastric bypass. ${ }^{10}$ 


\section{Conclusion}

Obesity is a major health care issue with currently no satisfactory pharmacologic or dietary solution. Bariatric surgery is the most effective long-term treatment for severe obesity. We have presented the available data on the profound effects of bariatric surgery on obesity-related comorbidities. When bariatric surgery is performed in $\mathrm{COE}$, the rate of mortality is comparable with the one of the common general surgical procedures such as cholecystectomy. The resolution of or improvement in the obesity-related health problems has repercussion for longer life expectancy. Expectations of patients should be carefully managed as bariatric surgery is unlikely to make patients thin or happy but should rather be seen as a tool to make patients healthier and more functional.

\section{Disclosure}

The authors report no conflicts of interest in this work.

\section{References}

1. World Health Organization. Overweight and obesity. Fact Sheet No 311. Geneva, Switzerland: WHO; 2006.

2. Haslam DW, James WP. Obesity. Lancet. 2005;366(9492): 1197-1209.

3. Sjöström L, Lindroos AK, Peltonen M, et al. Lifestyle, diabetes, and cardiovascular risk factors 10 years after bariatric surgery. $N$ Engl $J$ Med. 2004;351(26):2683-2693.

4. Tsai AG, Wadden TA. Systematic review: an evaluation of major commercial weight loss programs in the United States. Ann Intern Med. 2005;142(1):56-66.

5. Rucker D, Padwal R, Li SK, Curioni C, Lau DC. Long term pharmacotherapy for obesity and overweight: updated meta-analysis. $B M J$. 2007;335(7631):1194-1199.

6. Dixon JB, O'Brien PE, Playfair J, et al. Adjustable gastric banding and conventional therapy for type 2 diabetes: a randomized controlled trial. JAMA. 2008;299(3):316-323.

7. Mingrone G, Greco AV, Giancaterini A, Scarfone A, Castagneto M, Pugeat M. Sex hormone-binding globulin levels and cardiovascular risk factors in morbidly obese subjects before and after weight reduction induced by diet or malabsorptive surgery. Atherosclerosis. 2002;161(2):455-462.

8. O'Brien PE, Dixon JB, Laurie C, et al. Treatment of mild to moderate obesity with laparoscopic adjustable gastric banding or an intensive medical program: a randomized trial. Ann Intern Med. 2006;144(9):625-633.

9. Fontaine KR, Redden DT, Wang C, Westfall AO, Allison DB. Years of life lost due to obesity. JAMA. 2003;289(2):187-193.

10. Sjöström L, Narbro K, Sjöström CD, et al. Effects of bariatric surgery on mortality in Swedish obese subjects. $N$ Engl $\mathrm{J} \mathrm{Med}$. 2007;357(8):741-752.

11. Adams TD, Gress RE, Smith SC, et al. Long-term mortality after gastric bypass surgery. N Engl J Med. 2007;357(8):753-761.

12. Flum DR, Dellinger EP. Impact of gastric bypass operation on survival: a population-based analysis. J Am Coll Surg. 2004;199(4):543-551.

13. Christou NV, Sampalis JS, Liberman M, et al. Surgery decreases long-term mortality, morbidity, and health care use in morbidly obese patients. Ann Surgery. 2004;240(3):416-423.

14. Buchwald H, Oien DM. Metabolic/bariatric surgery worldwide 2008. Obes Surg. 2009;19(12):1605-1611.
15. Scopinaro N, Gianetta E, Civalleri D, Bonalumi U, Bachi V. Biliopancreatic bypass for obesity: II. Initial experience in man. Br J Surg. 1979;66(9):618-620.

16. Smith BR, Schauer P, Nguyen NT. Surgical approaches to the treatment of obesity: bariatric surgery. Endocrinol Metab Clin North Am 2008;37(4):943-964.

17. Mingrone G. Role of the incretin system in the remission of type 2 diabetes following bariatric surgery. Nutr Metab Cardiovasc Dis. 2008;18(8):574-579.

18. Mingrone G, Castagneto M. Bariatric surgery: unstressing or boosting the beta-cell? Diabetes Obes Metab. 2009;11 Suppl 4:130-142.

19. O'Brien PE, Dixon JB, Laurie C, Anderson M. A prospective randomized trial of placement of the laparoscopic adjustable gastric band: comparison of the perigastric and pars flaccida pathways. Obes Surg. 2005;15(6):820-826.

20. Akkary E, Duffy A, Bell R. Deciphering the sleeve: technique, indications, efficacy, and safety of sleeve gastrectomy. Obes Surg. 2008;18(10):1323-1329.

21. Scopinaro N, Gianetta E, Pandolfo N, Anfossi A, Berretti B, Bachi V. Bilio-pancreatic bypass. Proposal and preliminary experimental study of a new type of operation for the functional surgical treatment of obesity. Minerva Chir. 1976;31(10):560-566.

22. Ali MR, Fuller WD, Choi MP, Wolfe BM. Bariatric surgical outcomes. Surg Clin North Am. 2005;85(4):835-852.

23. Hess DS, Hess DW. Biliopancreatic diversion with a duodenal switch. Obes Surg. 1998 Jun;8(3):267-282.

24. Aylwin S, Al-Zaman Y. Emerging concepts in the medical and surgical treatment of obesity. Front Horm Res. 2008;36:229-259.

25. Kuruba R, Koche LS, Murr MM. Preoperative assessment and perioperative care of patients undergoing bariatric surgery. Med Clin North Am. 2007;91(3):339-351.

26. Frey WC, Pilcher J. Obstructive sleep-related breathing disorders in patients evaluated for bariatric surgery. Obes Surg. 2003; 13(5):676-683.

27. O'Keeffe T, Patterson EJ. Evidence supporting routine polysomnography before bariatric surgery. Obes Surg. 2004;14(1):23-26.

28. Greenburg DL, Lettieri CJ, Eliasson AH. Effects of surgical weight loss on measures of obstructive sleep apnea: a meta-analysis. Am J Med. 2009;122(6):535-542.

29. Buchwald H, Avidor Y, Braunwald E, et al. Bariatric surgery: a systematic review and meta-analysis. JAMA. 2004;292(14):1724-1737.

30. Chinn S, Downs SH, Anto JM, et al. Incidence of asthma and net change in symptoms in relation to changes in obesity. Eur Respir J. 2006;28(4):763-771.

31. Beuther DA, Weiss ST, Sutherland ER. Obesity and asthma. Am J Respir Crit Care Med. 2006;174(2):112-119.

32. Camargo CA Jr, Weiss ST, Zhang S, Willett WC, Speizer FE. Prospective study of body mass index, weight change, and risk of adult-onset asthma in women. Arch Intern Med. 1999;159(21):2582-2588.

33. Pories WJ. Bariatric surgery: risks and rewards. J Clin Endocrinol Metab. 2008;93(11 Suppl 1):S89-S96.

34. Dixon JB, Chapman L, O'Brien P. Marked improvement in asthma after Lap-Band surgery for morbid obesity. Obes Surg. 1999;9(4):385-389.

35. Maggard MA, Shugarman LR, Suttorp M, et al. Meta-analysis: surgical treatment of obesity. Ann Intern Med. 2005;142(7):547-559.

36. Brethauer SA, Hammel JP, Schauer PR. Systematic review of sleeve gastrectomy as staging and primary bariatric procedure. Surg Obes Relat Dis. 2009;5(4):469-475.

37. Karamanakos SN, Vagenas K, Kalfarentzos F, Alexandrides TK Weight loss, appetite suppression, and changes in fasting and postprandial ghrelin and peptide-YY levels after Roux-en-Y gastric bypass and sleeve gastrectomy: a prospective, double blind study. Ann Surg. 2008;247(3):401-7.

38. Himpens J, Dapri G, Cadiere GB. A prospective randomized study between laparoscopic gastric banding and laparoscopic isolated sleeve gastrectomy: results after 1 and 3 years. Obes Surg. 2006;16(11): $1450-1456$. 
39. Angrisani L, Lorenzo M, Borrelli V. Laparoscopic adjustable gastric banding versus Roux-en-Y gastric bypass: 5-year results of a prospective randomized trial. Surg Obes Relat Dis. 2007;3(2):127-132.

40. Lakka HM, Laaksonen DE, Lakka TA, et al. The metabolic syndrome and total and cardiovascular disease mortality in middle-aged men. JAMA. 2002;288(21):2709-2716.

41. Meigs JB, Wilson PW, Fox CS, et al. Body mass index, metabolic syndrome, and risk of type 2 diabetes or cardiovascular disease. J Clin Endocrinol Metab. 2006;91(8):2906-2912.

42. Karason K, Wikstrand J, Sjostrom L, Wendelhag I. Weight loss and progression of early atherosclerosis in the carotid artery: a four-year controlled study of obese subjects. Int J Obes Relat Metab Disord. 1999;23(9):948-956.

43. Alpert MA, Lambert CR, Panayiotou H, et al. Relation of duration of morbid obesity to left ventricular mass, systolic function, and diastolic filling, and effect of weight loss. Am J Cardiol. 1995;76(16):1194-1197.

44. Zarich SW, Kowalchuk GJ, McGuire MP, Benotti PN, Mascioli EA, Nesto RW. Left ventricular filling abnormalities in asymptomatic morbid obesity. Am J Cardiol. 1991;68(4):377-381.

45. Mathier MA, Ramanathan RC. Impact of obesity and bariatric surgery on cardiovascular disease. Med Clin North Am. 2007;91(3): 415-431.

46. Poirier P, Martin J, Marceau P, Biron S, Marceau S. Impact of bariatric surgery on cardiac structure, function and clinical manifestations in morbid obesity. Expert Rev Cardiovasc Ther. 2004;2(2):193-201.

47. Ashrafian H, le Roux CW, Darzi A, Athanasiou T. Effects of bariatric surgery on cardiovascular function. Circulation. 2008;118(20): 2091-2102.

48. Dixon JB. Obesity and diabetes: the impact of bariatric surgery on type-2 diabetes. World J Surg. 2009;33(10):2014-2021.

49. Astrup A, Finer N. Redefining type 2 diabetes: 'diabesity' or 'obesity dependent diabetes mellitus'? Obes Rev. 2000;1(2):57-59.

50. Leibson CL, Williamson DF, Melton LJ III, et al. Temporal trends in BMI among adults with diabetes. Diabetes Care. 2001;24(9):1584-1589.

51. Fetner R, McGinty J, Russell C, Pi-Sunyer FX, Laferrère B. Incretins, diabetes, and bariatric surgery: a review. Surg Obes Relat Dis. 2005;1(6):589-597.

52. Buse JB, Caprio S, Cefalu WT, et al. How do we define cure of diabetes? Diabetes Care. 2009;32(11):2133-2135.

53. Buchwald H, Estok R, Fahrbach K, et al. Weight and type 2 diabetes after bariatric surgery: systematic review and meta-analysis. Am J Med. 2009;122(3):248-256.

54. Bose M, Oliván B, Teixeira J, Pi-Sunyer FX, Laferrère B. Do incretins play a role in the remission of type 2 diabetes after gastric bypass surgery: what are the evidence? Obes Surg. 2009;19(2):217-229.

55. Puhl R, Brownell KD. Bias, discrimination, and obesity. Obes Res. 2001;9(12):788-805.

56. Herpertz S, Kielmann R, Wolf AM, Langkafel M, Senf W, Hebebrand J. Does obesity surgery improve psychosocial functioning? A systematic review. Int J Obes Relat Metab Disord. 2003;27(11): 1300-1314.

57. Näslund II, Ågren G. Social and Economic Effects of Bariatric Surgery. Obes Surg. 1991;1(2):137-140.

58. Narbro K, Agren G, Jonsson E, et al. Sick leave and disability pension before and after treatment for obesity: a report from the Swedish Obese Subjects (SOS) study. Int J Obes Relat Metab Disord. 1999;23:619-624.

59. Narbro K, Agren G, Jonsson E, Näslund I, Sjöström L, Peltonen M. Pharmaceutical costs in obese individuals: comparison with a randomly selected population sample and long-term changes after conventional and surgical treatment: the SOS intervention study. Arch Intern Med. 2002;162(18):2061-2069.

60. Cremieux PY, Buchwald H, Shikora SA, Ghosh A, Yang HE, Buessing M. A study on the economic impact of bariatric surgery. Am J Manag Care. 2008;14(9):589-596.
61. Wadden TA, Sarwer DB, Fabricatore AN, Jones L, Stack R, Williams NS. Psychosocial and behavioral status of patients undergoing bariatric surgery: what to expect before and after surgery. Med Clin North Am. 2007;91(3):451-469.

62. Peltonen M, Lindroos AK, Torgerson JS. Musculoskeletal pain in the obese: a comparison with a general population and long-term changes after conventional and surgical obesity treatment. Pain. 2003;104(3):549-557.

63. McGoey BV, Deitel M, Saplys RJ, Kliman ME. Effect of weight loss on musculoskeletal pain in the morbidly obese. J Bone Joint Surg Br. 1990;72(2):322-323.

64. Melissas J, Volakakis E, Hadjipavlou A. Low-back pain in morbidly obese patients and the effect of weight loss following surgery. Obes Surg. 2003;13(3):389-393.

65. Pasquali R, Patton L, Gambineri A. Obesity and infertility. Curr Opin Endocrinol Diabetes Obes. 2007;14(6):482-487.

66. Gosman GG, King WC, Schrope B, et al. Reproductive health of women electing bariatric surgery. Fertil Steril. 2009 Oct 6. [Epub ahead of print.]

67. Deitel M, Stone E, Kassam HA, Wilk EJ, Sutherland DJ. Gynecologicobstetric changes after loss of massive excess weight following bariatric surgery. J Am Coll Nutr. 1988;7(2):147-153.

68. Dixon JB, Dixon ME, O’Brien PE. Pregnancy after Lap-Band surgery: management of the band to achieve healthy weight outcomes. Obes Surg. 2001;11(1):59-65.

69. Patel JA, Colella JJ, Esaka E, Patel NA, Thomas RL. Improvement in infertility and pregnancy outcomes after weight loss surgery. Med Clin North Am. 2007;91(3):515-528.

70. Eid GM, Cottam DR, Velcu LM, et al. Effective treatment of polycystic ovarian syndrome with Roux-en-Y gastric bypass. Surg Obes Relat Dis. 2005;1(2):77-80.

71. Escobar-Morreale HF, Botella-Carretero JI, Alvarez-Blasco F, Sancho J, San Millan JL. The polycystic ovary syndrome associated with morbid obesity may resolve after weight loss induced by bariatric surgery. J Clin Endocrinol Metab. 2005;90(12):6364-6369.

72. Morin KH. Perinatal outcomes of obese women: a review of the literature. J Obstet Gynecol Neonatal Nurs. 1998;27(4):431-440.

73. Gross T, Sokol RJ, King KC. Obesity in pregnancy: risks and outcome. Obstet Gynecol. 1980;56(4):446-450.

74. Merhi ZO. Impact of bariatric surgery on female reproduction. Fertil Steril. 2009;92(5):1501-1508.

75. Maggard MA, Yermilov I, Li Z, et al. Pregnancy and fertility following bariatric surgery: a systematic review. JAMA. 2008;300(19): 2286-2296.

76. Karlsson J, Taft C, Ryden A, Sjostrom L, Sullivan M. Ten-year trends in health-related quality of life after surgical and conventional treatment for severe obesity: the SOS intervention study. Int J Obes (Lond). 2007;31(8):1248-1261.

77. Kolotkin RL, Crosby RD, Gress RE, Hunt SC, Adams TD. Two-year changes in health-related quality of life in gastric bypass patients compared with severely obese controls. Surg Obes Relat Dis. 2009;5(2):250-256.

78. Adami GF, Meneghelli A, Bressani A, Scopinaro N. Body image in obese patients before and after stable weight reduction following bariatric surgery. J Psychosom Res. 1999;46(3):275-281.

79. Sallet PC, Sallet JA, Dixon JB, et al. Eating behaviour as a prognostic factor for weight loss after gastric bypass. Obes Surg. 2007; 17(4):445-451.

80. Busetto L, Segato G, de Luca M, et al. Weight loss and postoperative complications in morbidly obese patients with binge eating disorder treated by laparoscopic adjustable gastric banding. Obes Surg. 2005;15(2):195-201

81. Hsu LK, Sullivan SP, Benotti PN. Eating disturbances and outcome of gastric bypass surgery: a pilot study. Int $J$ Eat Disord. 1997;21(4):385-390.

82. Colles SL, Dixon JB, O’Brien PE. Grazing and loss of control related to eating: two high-risk factors following bariatric surgery. Obesity. 2008;16(3):615-622. 
83. Scholtz S, Bidlake L, Morgan J, et al. Long-term outcomes following laparoscopic adjustable gastric banding: postoperative psychological sequelae predict outcome at 5-year follow-up. Obes Surg. 2007;17(9):1220-1225.

84. Corley DA, Kubo A. Body mass index and gastroesophageal reflux disease: a systematic review and meta-analysis. Am J Gastroenterol. 2006;101(11):2619-2628.

85. El-Serag H. The association between obesity and GERD: a review of the epidemiological evidence. Dig Dis Sci. 2008;53(9):2307-2312.

86. Wong A, Fitzgerald RC. Epidemiologic risk factors for Barrett's esophagus and associated adenocarcinoma. Clin Gastroenterol Hepatol. 2005;3(1):1-10.

87. Nelson LG, Gonzalez R, Haines K, Gallagher SF, Murr MM. Amelioration of gastroesophageal reflux symptoms following Rouxen-Y gastric bypass for clinically significant obesity. Am Surg. 2005;71(11):950-953.

88. Frezza EE, Ikramuddin S, Gourash W, et al. Symptomatic improvement in gastroesophageal reflux disease (GERD) following laparoscopic Roux-en-Y gastric bypass. Surg Endosc. 2002;16(7):1027-1031.

89. Dixon JB, O'Brien PE. Gastroesophageal reflux in obesity: the effect of lap-band placement. Obes Surg. 1999;9(6):527-531.

90. Gutschow CA, Collet P, Prenzel K, Hölscher AH, Schneider PM. Long-term results and gastroesophageal reflux in a series of laparoscopic adjustable gastric banding. J Gastrointest Surg. 2005;9(7) 941-948.

91. de Jong JR, Besselink MG, van Ramshorst B, Gooszen HG, Smout AJ. Effects of adjustable gastric banding on gastroesophageal reflux and esophageal motility: a systematic review. Obes Rev. 2010;11(4): 297-305. Epub 2009 Jun 26.

92. Braghetto I, Lanzarini E, Korn O, Valladares H, Molina JC, Henriquez A. Manometric changes of the lower esophageal sphincter after sleeve gastrectomy in obese patients. Obes Surg. 2010;20(3): 357-362. Epub 2009 Dec 15.

93. Soricelli E, Casella G, Rizzello M, Calì B, Alessandri G, Basso N. Initial experience with laparoscopic crural closure in the management of hiatal hernia in obese patients undergoing sleeve gastrectomy. Obes Surg. 2010;20(8):1149-1153.

94. Csendes A, Burgos AM, Smok G, Burdiles P, Henriquez A. Effect of gastric bypass on Barrett's esophagus and intestinal metaplasia of the cardia in patients with morbid obesity. J Gastrointest Surg. 2006; 10(2):259-264

95. Houghton SG, Romero Y, Sarr MG. Effect of Roux-en-Y gastric bypass in obese patients with Barrett's esophagus: attempts to eliminate duodenogastric reflux. Surg Obes Relat Dis. 2008;4(1):1-4.

96. Adelman RD. Obesity and renal disease. Curr Opin Nephrol Hypertens. 2002;11(3):331-335.

97. Fox CS, Larson MG, Leip EP, Culleton B, Wilson PW, Levy D. Predictors of new-onset kidney disease in a community-based population. JAMA. 2004;291(7):844-850.

98. Navarro-Díaz M, Serra A, Romero R, et al. Effect of drastic weight loss after bariatric surgery on renal parameters in extremely obese patients: long-term follow-up. JAm Soc Nephrol. 2006;17(12 Suppl 3): S213-S217.

99. Afshinnia F, Wilt TJ, Duval S, Esmaeili A, Ibrahim HN. Weight loss and proteinuria: systematic review of clinical trials and comparative cohorts. Nephrol Dial Transplant. 2010;25(4):1173-1183.

100. Zalesin KC, McCullough PA. Bariatric surgery for morbid obesity: risks and benefits in chronic kidney disease patients. Adv Chronic Kidney Dis. 2006;13(4):403-417

101. Navaneethan SD, Yehnert H. Bariatric surgery and progression of chronic kidney disease. Surg Obes Relat Dis. 2009;5(6):662-665. Epub 2009 Jan 28.

102. Machado M, Marques-Vidal P, Cortez-Pinto H. Hepatic histology in obese patients undergoing bariatric surgery. $J$ Hepatol. 2006;45(4):600-606.

103. Li Z, Clark J, Diehl AM. The liver in obesity and type 2 diabetes mellitus. Clin Liver Dis. 2002;6(4):867-877.
104. Dixon JB, Bhathal PS, Hughes NR, O'Brien PE. Nonalcoholic fatty liver disease: Improvement in liver histological analysis with weight loss. Hepatology. 2004;39(6):1647-1654.

105. Mottin CC, Moretto M, Padoin AV, et al. Histological behavior of hepatic steatosis in morbidly obese patients after weight loss induced by bariatric surgery. Obes Surg. 2005;15(6):788-793.

106. Mummadi RR, Kasturi KS, Chennareddygari S, Sood GK. Effect of bariatric surgery on nonalcoholic fatty liver disease: systematic review and meta-analysis. Clin Gastroenterol Hepatol. 2008;6(12):1396-1402.

107. Bardel A, Wallander MA, Svärdsudd K. Reported current use of prescription drugs and some of its determinants among 35 to 65 -year-old women in mid-Sweden: A population-based study. J Clin Epidemiol. 2000;53(6):637-643.

108. Nguyen NT, Varela JE, Sabio A, Naim J, Stamos M, Wilson SE. Reduction in prescription medication costs after laparoscopic gastric bypass. Am Surg. 2006;72(10):853-856.

109. Ahroni JH, Montgomery KF, Watkins BM. Laparoscopic adjustable gastric banding: weight loss, co-morbidities, medication usage and quality of life at one year. Obes Surg. 2005;15(5):641-647.

110. Olbers T, Björkman S, Lindroos A, Maleckas A, Lönn L, Sjöström L. Body composition, dietary intake, and energy expenditure after laparoscopic Roux-en-Y gastric bypass and laparoscopic vertical banded gastroplasty: a randomized clinical trial. Ann Surg. 2006;244(5):715-722.

111. Karlsson J, Sjöström L, Sullivan M. Swedish obese subjects (SOS)-an intervention study of obesity. Two-year follow-up of health-related quality of life (HRQL) and eating behavior after gastric surgery for severe obesity. Int J Obes Relat Metab Disord. 1998;22(2):113-126

112. Renehan AG, Tyson M, Egger M, Heller RF, Zwahlen M. Body-mass index and incidence of cancer: a systematic review and meta-analysis of prospective observational studies. Lancet. 2008;371(9612):569-578.

113. Sjöström L, Gummesson A, Sjöström CD, et al. Effects of bariatric surgery on cancer incidence in obese patients in Sweden (Swedish Obese Subjects Study): a prospective, controlled intervention trial. Lancet Oncol. 2009;10(7):653-656.

114. Christou NV, Lieberman M, Sampalis F, Sampalis JS. Bariatric surgery reduces cancer risk in morbidly obese patients. Surg Obes Relat Dis. 2008;4(6):691-695.

115. McCawley GM, Ferriss JS, Geffel D, Northup CJ, Modesitt SC. Cancer in obese women: potential protective impact of bariatric surgery. J Am Coll Surg. 2009;208(6):1093-1098.

116. Buchwald H, Estok R, Fahrbach K, Banel D, Sledge I. Trends in mortality in bariatric surgery: a systematic review and meta-analysis. Surgery. 2007;142(4):621-632.

117. Flum DR, Belle SH, King WC, et al. for Longitudinal Assessment of Bariatric Surgery (LABS) Consortium. Perioperative safety in the longitudinal assessment of bariatric surgery. $N$ Engl J Med. 2009;361(5):445-454.

118. Melissas J. Safety, quality and excellence in bariatric surgery. Minerva Chir. 2009;64(3):239-252.

119. DeMaria EJ, Portenier D, Wolfe L. Obesity surgery mortality risk score: proposal for a clinically useful score to predict mortality risk in patients undergoing gastric bypass. Surg Obes Relat Dis. 2007; 3(2):134-140.

120. Murr MM, Martin T, Haines K, et al. A state-wide review of contemporary outcomes of gastric bypass in Florida: does provider volume impact outcomes? Ann Surg. 2007;245(5):699-706.

121. Allen JW. Laparoscopic gastric band complications. Med Clin North Am. 2007;91(3):485-497.

122. DeMaria EJ, Pate V, Warthen M, Winegar DA. Baseline data from American Society for Metabolic and Bariatric Surgery-designated Bariatric Surgery Centers of Excellence using the Bariatric Outcomes Longitudinal Database. Surg Obes Relat Dis. 2010;6(4):347-355.

123. Birkmeyer NJ, Dimick JB, Share D, et al; for Michigan Bariatric Surgery Collaborative. Hospital complication rates with bariatric surgery in Michigan. JAMA. 2010;304(4):435-442. 
124. Bult MJ, van Dalen T, Muller AF. Surgical treatment of obesity. Eur $J$ Endocrinol. 2008;158(2):135-145.

125. Brethauer SA, Chand B, Schauer PR. Risks and benefits of bariatric surgery: current evidence. Cleve Clin J Med. 2006;73(11):993-1007.

126. Podnos YD, Jimenez JC, Wilson SE, Stevens CM, Nguyen NT. Complications after laparoscopic gastric bypass: a review of 3464 cases. Arch Surg. 2003;138(9):957-961.

127. Nguyen NT, Wilson SE. Complications of antiobesity surgery. Nat Clin Pract Gastroenterol Hepatol. 2007;4(3):138-147.

128. Serra C, Baltasar A, Andreo L, et al. Treatment of gastric leaks with coated self-expanding stents after sleeve gastrectomy. Obes Surg. 2007;17(7):866-872.

129. Eubanks S, Edwards CA, Fearing NM, et al. Use of endoscopic stents to treat anastomotic complications after bariatric surgery. $\mathrm{J} \mathrm{Am} \mathrm{Coll}$ Surg. 2008;206(5):935-938.

130. Fujioka K. Follow-up of nutritional and metabolic problems after bariatric surgery. Diabetes Care. 2005;28(2):481-484.

131. Iannelli A, Facchiano E, Gugenheim J. Internal hernia after laparoscopic Roux-en-Y gastric bypass for morbid obesity. Obes Surg. 2006;16(10):1265-1271.

132. Bueter M, Maroske J, Thalheimer A, et al. Short- and long-term results of laparoscopic gastric banding for morbid obesity. Langenbecks Arch Surg. 2008;393(2):199-205.
133. O'Brien PE, Dixon JB. Weight loss and early and late complications the international experience. Am J Surg. 2002;184(6B):42S-45S.

134. Chapman AE, Kiroff G, Game P, et al. Laparoscopic adjustable gastric banding in the treatment of obesity: a systematic literature review. Surgery. 2004;135(3):326-351.

135. Sugerman HJ, Brewer WH, Shiffman ML, et al. A multicenter, placebo-controlled, randomized, double-blind, prospective trial of prophylactic ursodiol for the prevention of gallstone formation following gastric-bypass-induced rapid weight loss. Am J Surg. 1995;169(1):91-96.

136. Bouldin MJ, Ross LA, Sumrall CD, Loustalot FV, Low AK, Land KK. The effect of obesity surgery on obesity comorbidity. Am J Med Sci. 2006;331(4):183-193.

137. Monteforte MJ, Turkelson CM. Bariatric surgery for morbid obesity. Obes Surg. 2000;10(5):391-401.

138. Elder KA, Wolfe BM. Bariatric surgery: a review of procedures and outcomes. Gastroenterology. 2007;132(6):2253-2271.

139. Gehrer S, Kern B, Peters T, Christoffel-Courtin C, Peterli R. Fewer nutrient deficiencies after laparoscopic sleeve gastrectomy (LSG) than after laparoscopic Roux-Y-gastric bypass (LRYGB): a Prospective Study. Obes Surg. 2010;20(4):447-453. Epub 2010 Jan 26.

140. Frachetti KJ, Goldfine AB. Bariatric surgery for diabetes management. Curr Opin Endocrinol Diabetes Obes. 2009;16(2):119-124.
Open Access Surgery

\section{Publish your work in this journal}

Open Access Surgery is an international, peer-reviewed, open access journal that focuses on all aspects of surgical procedures and interventions. Patient care around the peri-operative period and patient outcomes post surgery are key topics. All grades of surgery from minor cosmetic interventions to major surgical procedures are covered. Novel techniques

Submit your manuscript here: http://www.dovepress.com/open-access-surgery-journal

\section{Dovepress}

and the utilization of new instruments and materials, including implants and prostheses that optimize outcomes constitute major areas of interest. The manuscript management system is completely online and includes a very quick and fair peer-review system. Visit http://www.dovepress.com/ testimonials.php to read real quotes from published authors. 